\title{
Unique Vesico-obturator Ligament and Its Functional and Surgical Importance
}

\author{
Satheesha B. Nayak ${ }^{1}$ \\ 'Department of Anatomy, Melaka Manipal Medical College (Manipal Campus), Manipal Academy of Higher Education, Manipal, Karnataka, India
}

Disclose and conflicts of interest: none to be declared by all author

\section{ABSTRACT}

The present report is about a unique vesico-obturator ligament observed in an adult male cadaver during dissection classes. The ligament extended from the inferolateral surface of the urinary bladder to the fascia covering the obturator internus. It was conical in shape and contained some veins running from the thigh to the vesical venous plexus. The obturator nerve and vessels had a normal course. Possibly, this is the first report on this type of ligament, and it might interfere in the normal micturition process and might also result in bleeding during various surgical procedures in and around the obturator foramen. Keywords: Obturator; Ligament; Pelvic fascia; Bladder; Hernia

\section{Introduction}

The pelvic fascia is situated above the pelvic diaphragm, and it condenses to form various ligaments of the pelvic organs. It thickens to form the puboprostatic ligaments, and the lateral and posterior ligaments of the bladder in males. On the lateral wall of the pelvis, it forms the tendinous arch, which gives origin to the levator ani muscle. It also condenses around the rectum to form its supports. It is extremely rare to see variations in the ligaments of the urinary bladder. In the literature, there are reports only on studies conducted on puboprostatic ligaments. ${ }^{1}$ The presence of additional ligaments might alter the functioning of the pelvic viscera, produce pain, or might cause problems in surgeries in the area. Here, a unique ligament between the bladder and the obturator foramen is being reported, and this might be the first report on such a ligament.

\section{Case Report}

During gross anatomy dissection classes for medical students, a unique vesico-obturator ligament was found in an adult male, aged $\sim 70$ years. The ligament was present on the right side of the midline and was unilateral. The ligament was conical in shape and extended from the inferolateral surface of the urinary bladder to the fascia covering the obturator internus muscle. It was made up of pelvic fascia and was situated $3 \mathrm{~cm}$ above the level of the base of prostate. The ligament was $2 \mathrm{~cm}$ long, $1.5 \mathrm{~cm}$ broad at its attachment on the bladder, and $0.5 \mathrm{~cm}$ at its attachment on the obturator fascia. Upon dissecting the ligament, it was noted that a few small veins passed from the thigh to the bladder wall and from there upon to the vesical venous plexus. The obturator foramen transmitted the obturator nerve and vessels as usual. The variant ligament is shown in Figs. 1 and 2.

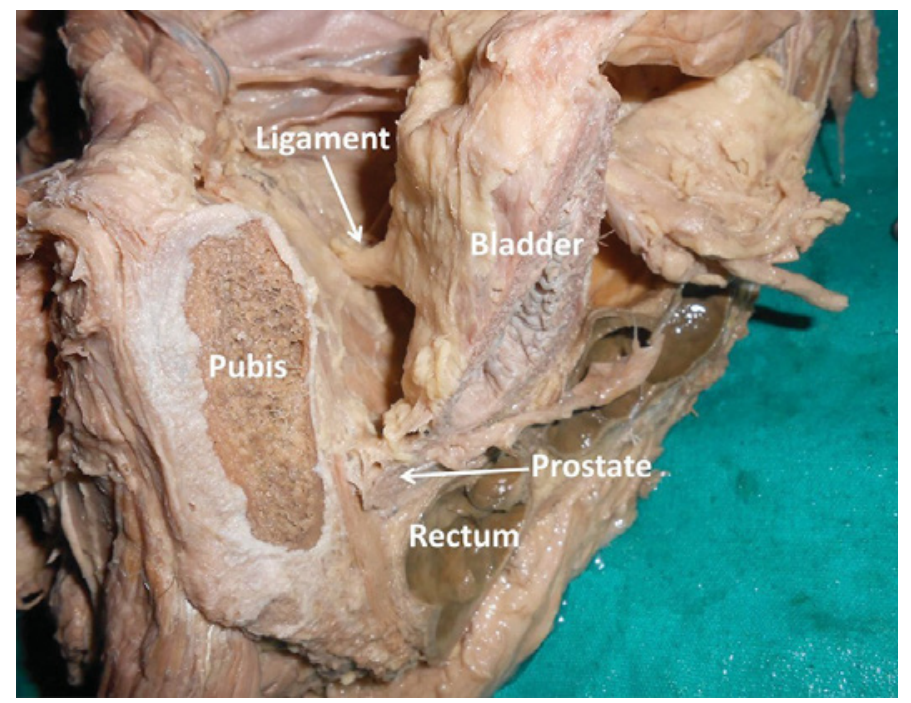

Figure 1. Dissection of the right hemipelvis (viewed from above) showing the vesico-obturator ligament. Abbreviations: EIV, External iliac vein; EIA, external iliac artery.

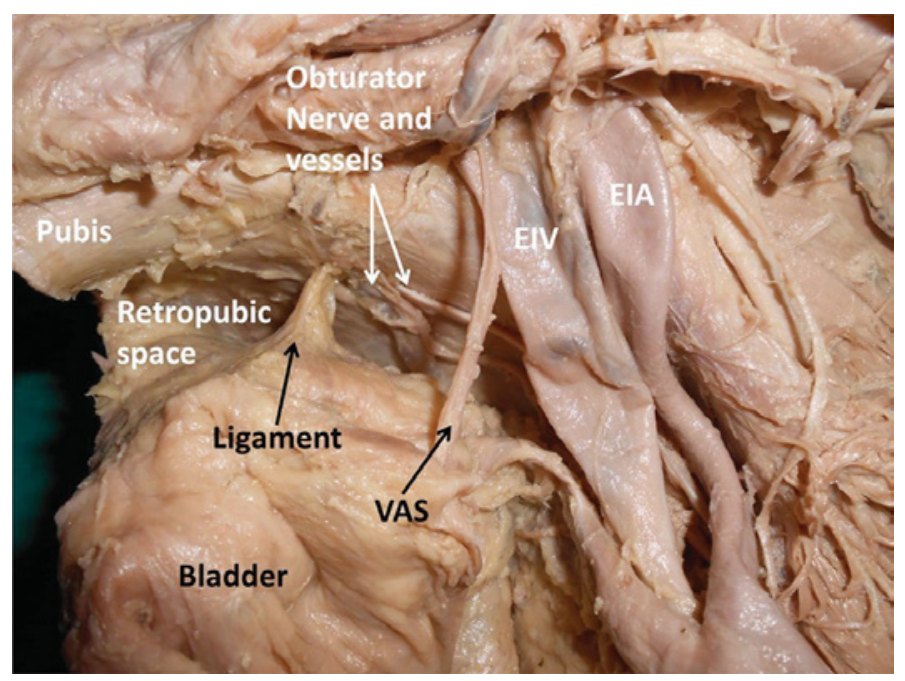

Figure 2. Superior view of the variant ligament. 


\section{Discussion}

Knowledge of anatomic variations in and around the obturator foramen is of importance to gynecologists, orthopedic surgeons, urologists, surgeons, and radiologists. The current case deals with an unusual ligament extending from the bladder to the fascia covering the obturator internus muscle. The ligament being reported here cannot be classified as a variant of the puboprostatic ligament, since it has not been reported in previous studies on puboprostatic ligament variants classifications.1 This ligament might cause pelvic myofascial pain or hip and groin pain, as there are reports on pain caused by fascial variants of the pelvis. This pain can be reduced by pelvic myofascial manipulations. ${ }^{2,3}$ During reduction of obturator hernia and placing hernia mesh, this ligament might get damaged, causing iatrogenic bleeding from the veins present in the ligament, ${ }^{4}$ Doctors involved in transobturator sling or trocar placement procedure should be aware of the presence of a ligament in the vicinity of the obturator foramen. The ligament might provide resistance in the procedure or might get ruptured during the procedure. ${ }^{5,6}$ Surgeons involved in obturator foramen approach for reconstruction of vas deference also must be aware of the existence of this ligament, ${ }^{7}$ Surgeons involved in the removal of obturator foramen masses or of ganglionic cysts are also required to know about the presence of this abnormal ligament. ${ }^{8}$ This ligament might surprise radiologists during scanning procedures due to its size and rarity. It might lead to diagnostic dilemmas. The ligament might produce fascial pain in the groin or thigh, and might also interfere in the normal functioning of the urinary bladder, since one of its ends was attached to the bladder. Filling and emptying of the bladder might be affected by this ligament. It might be more dangerous if found in a female, due to the variety of gynecological procedures in this region.

\section{Conclusion}

The vesico-obturator ligament being reported here is unique in its attachments and contained veins. Possibly, this is the first report on such a ligament. It might cause functional, diagnostic, and surgical problems in the individual who has it.

\section{References}

1. Kim M, Boyle SL, Fernandez A, et al. Development of a novel classification system for anatomical variants of the puboprostatic ligaments with expert validation. Can Urol Assoc J 2014;8 (1112):432-436.

2. Bonder JH, Chi M, Rispoli L. Myofascial Pelvic Pain and Related Disorders. Phys Med Rehabil Clin N Am 2017;28(03):501-515.

3. Navot S, Kalichman L. Hip and groin pain in a cyclist resolved after performing a pelvic floor fascial mobilization. J Bodyw Mov Ther 2016;20(03):604-609.

4. Oviedo RJ, Molinari AHW. Emergency incarcerated obturator hernia repair with biologic mesh in a male patient after ipsilateral hip disarticulation: A case report. Int J Surg Case Rep 2017; 37:41-44.
5. Cohen D, Delmas V, Boccon-Gibod L. [Anatomy of obturated foramen. Application to trans-obturator slings]. Prog Urol 2005; 15(04):693-699.

6. Ottem D, Stothers L. Transobturator tape: variation in the vascular anatomy of the obturator foramen. Can J Urol 2007;14(05): 3678-3683 7. Shafik A. Obturator foramen approach. I. A new technique for reconstruction of the vas deferens after extensive resections. Am J Surg 1982;143(02):255-259.

8. de Bruijn KM, Franssen G, van Ginhoven TM. A stepwise approach to 'groin pain': a common symptom, an uncommon cause. BMJ Case Rep 2013;2013:2013.
Received: September 5, 2018

Accepted: August 14, 2019
Corresponding author

Satheesha B. Nayak

Email: sathish.nayak@manipal.edu 